\title{
A Emenda Constitucional dos Precatórios: Histórico, Incentivos e Leilões de Deságio*
}

\author{
Maurício Bugarin \\ Professor - Centro de Investigação em Economia e Finanças e Departamento de Economia \\ da Universidade de Brasília \\ Endereço para contato: Campus Universitário Darcy Ribeiro - ICC Norte, Ala Norte \\ Brasília - DF - CEP: 70910-900 - E-mail: bugarin@unb.br
}

\author{
Fernando Meneguin \\ Consultor Legislativo - Núcleo de Estudos e Pesquisas Senado Federal \\ Endereço para contato: Praça dos Três Poderes - Senado, Anexo II, BI. B \\ $2^{\circ}$ Andar/Consultoria Legislativa - Brasília - DF \\ CEP: 70165-900 - E-mail: fbmeneguin@hotmail.com
}

Recebido em 28 de agosto de 2012. Aceito em 04 de outubro de 2012.

\begin{abstract}
Resumo
A questão dos precatórios se transformou em problema de magnitude nacional, comprometendo o bom funcionamento das instituições republicanas. Por um lado, estados e municípios se recusavam a pagá-los, argumentando insuficiência de verbas. Por outro lado, os credores exigiam o respeito a um direito legal. Uma nova legislação, a Emenda Constitucional $n^{\circ} 62$, aprovada em 2009, estabeleceu um orçamento anual reservado ao pagamento de precatórios, bem como o uso de mecanismos de redução da dívida para ordenação de parte desse pagamento. Este artigo desenvolve uma análise econômica da Emenda Constitucional, que explica o apoio recebido pelos representantes dos estados e dos municípios no Congresso. Além disso, o artigo propõe e analisa uma forma específica para os leilões, baseando-se no formato dos leilões de Vickrey generalizados, que reduzem a dívida e o tempo necessário para seu pagamento.
\end{abstract}

\section{Palavras-Chave}

precatórios, finanças públicas, desenho de mecanismos, leilões

\begin{abstract}
Court-ordered debt payments have become a national problem in Brazil. On one hand, states and municipalities refused paying this debt, claiming limited revenue. On the other, creditors demanded the nation to secure their judicial right. A new constitutional amendment passed in 2009 establishes a fixed yearly budget for debt payment and debt-reduction auctions to decide who should first receive payment. This article presents an economic analysis of the bill and shows that it satisfies states and municipalities participation constraints. Moreover, it proposes and analyzes a generalized-Vickrey debt-reduction auction that satisfies creditors' participation constraints, reduces debt and the time needed for total debt payment.
\end{abstract}

- Os autores agradecem a Marcos Mendes e Paulo Barelli por comentários e sugestões a versões anteriores deste trabalho. Os erros remanescentes são de inteira responsabilidade dos autores. 


\section{Keywords}

court-ordered debt payments, public finance, mechanism design, auctions

\section{JEL Classification}

D44, D02, E62, H63, C72

\section{Introdução}

Publicam-se frequentemente na mídia matérias divulgando que estados e municípios brasileiros possuem dívidas acumuladas crescentes referentes a precatórios ${ }^{1}$ não pagos de exercícios anteriores. Tal constatação é consequência de se ter um fluxo de pagamentos menor do que o fluxo de novos precatórios, o que faz com que a dívida cresça ao longo do tempo.

A legislação traz sanções para as unidades da federação que não pagarem seus precatórios; no entanto, como esse comportamento está disseminado por quase todos os estados e municípios, o uso dessas punições tem sido limitado. Os governos estaduais e municipais justificam o não pagamento com dois argumentos: em primeiro lugar, argumentam que a legislação lhes impõe a execução de diversas despesas de caráter obrigatório, como saúde, educação, manutenção dos Poderes Legislativo e Judiciário, entre outras, não restando recursos para quitar precatórios, a menos que se comprometa o funcionamento cotidiano da máquina pública; em segundo lugar, contestam os cálculos de reajustes das dívidas pelo Judiciário, em especial a incidência de juros abusivos.

O problema já existe há bastante tempo. O que se fazia até então para lidar com as restrições financeiras dos entes públicos era o parcelamento dos débitos. Os constituintes de 1988 facultaram aos governos parcelar os precatórios então pendentes de pagamento em até oito anos. Posteriormente, a Emenda Constitucional $\mathrm{n}^{\mathrm{o}}$ 30, de 2000, autorizou outro parcelamento, dessa vez por dez anos. Tais parcelamentos, embora tenham aliviado o fluxo de caixa das entidades públicas devedoras, contribuíram para o acúmulo da dívida, uma vez que novos precatórios continuavam a entrar na fila

1 Precatório consiste em uma carta de sentença remetida pelo juiz da causa ao Presidente do Tribunal, para que este requisite ao Poder Executivo, mediante previsão na lei orçamentária anual, o pagamento de quantia certa para satisfazer obrigação decorrente de condenação da União, dos Estados, do DF ou dos Municípios. 
de pagamento. Ademais, a expectativa de que novos parcelamentos viessem a ser decretados estimulava os administradores públicos a não honrar a tempo suas dívidas, para gozar, no futuro, do benefício do parcelamento.

Por outro lado, temos a figura dos credores que, em muitos casos, haviam sido realmente lesados pelo Poder Público, ganharam direito a serem indenizados, mas aguardam por anos pela quitação dos créditos, sobretudo os de natureza alimentar, que decorrem de litígios relativos a salários e benefícios previdenciários. Muitos desses credores são pessoas idosas que não podem esperar para receber o que lhes é devido.

O não pagamento de precatórios, conforme explica Florenzano (2005), constitui problema complexo de várias facetas. "É um problema jurídico, porque o não pagamento dos precatórios configura um descumprimento de decisões judiciais transitadas em julgado. Ora, se o próprio Estado não cumpre as decisões judiciais, não se pode sequer falar em Estado de Direito. É também, no entanto, um problema econômico, porque afeta o desenvolvimento da atividade econômica e diz respeito à alocação de recursos escassos. É, ainda, um problema social, porque envolve a distribuição e aplicação de recursos públicos.”

Para se ter ideia da dimensão da discussão, segundo o Supremo Tribunal Federal - STF, ${ }^{2}$ estados, Distrito Federal e municípios devem $\mathrm{R} \$ 78$ bilhões em precatórios, o que equivale a aproximadamente 3\% do PIB nacional em 2007. Do total, 42,2 bilhões são precatórios alimentares e o restante, decorrente, por exemplo, de desapropriações de terras e imóveis. Apenas o estado de São Paulo deve $\mathrm{R} \$ 13$ bilhões, correspondente a cerca de 1,8\% do PIB estadual em 2005. ${ }^{3}$

Para complicar ainda mais a situação, a Justiça vem determinando o sequestro de rendas de estados e municípios para o pagamento de

2 Levantamento realizado até dez/2004, com atualização até dez/2007.

3 Em setembro de 2010 foi realizado em Brasília o Encontro Nacional do Judiciário sobre Precatórios, por iniciativa do Conselho Nacional de Justiça. Nessa ocasião circulou pela mídia um levantamento que teria sido feito pelo CNJ e que estimou que estados, Distrito Federal e municípios deviam em 2009 montante superior a R $\$ 84$ bilhões em precatórios, o que equivale mais de 2,6\% do PIB nacional nesse ano (vide Valor Econômico, 25/11/2011). Contactado pelos autores, o CNJ informou não dispor de nenhuma estimativa oficial. Portanto, os cálculos neste artigo se baseiam exclusivamente nos dados oficiais fornecidos pelo STF. 
parcelas de precatórios não alimentares, atitude que começa a ser referendada pelo STF. Conforme matéria publicada no jornal Valor Econômico, " "desde 2005, o tribunal proferiu algumas decisões cautelares suspendendo o sequestro de receitas de prefeituras para pagar precatórios não alimentares, sempre sob a alegação de risco de grave lesão aos cofres públicos e somente quando os valores sequestrados eram comprovadamente altos. A posição começou a mudar em outubro de 2006, quando foi julgado o mérito de uma reclamação do município de Diadema contra uma decisão da Justiça que determinou o sequestro de renda para pagar um precatório não alimentar. Ao julgar o mérito, o pleno do Supremo manteve o sequestro."

Resumindo o dilema, não é viável, por razões práticas, econômicas e financeiras, forçar o pagamento, de forma brusca, da dívida referente a precatórios. Por outro lado, também não é aceitável que a decisão de pagar as dívidas fique entregue ao livre arbítrio do Poder Executivo. Nesse contexto, várias proposições tramitaram no Congresso Nacional, tentando alterar a legislação de forma a equacionar os diversos problemas. Entre as proposições de mudança da legislação dos precatórios no Congresso Nacional, destacou-se a Proposta de Emenda à Constituição no 12, de 2006 (PEC 12/2006). Tal proposta foi elaborada pelo então presidente do STF, Nelson Jobim, alegando não poder punir os governantes inadimplentes e reconhecendo a necessidade de garantir o direito dos credores, e protocolada no Senado pelo senador Renan Calheiros. Após muitas discussões e emendas, a PEC 12/2006 deu origem, em 9 de dezembro de 2009, à Emenda Constitucional no 62 (EC no 62, de 2009), que institui "regime especial de pagamentos de precatórios pelos Estados, Distrito Federal e Municípios".

Diante desse contexto, o objetivo do presente trabalho é analisar a nova sistemática dos precatórios, considerando o valor das dívidas, e elaborar um modelo econômico que consiga avaliar se a regra estabelecida estimula a participação dos agentes envolvidos. Para tanto, a abordagem metodológica empregada é a teoria de desenho de mecanismos. Em sua formulação abstrata, um mecanismo consiste de uma regra de comunicação entre os agentes envolvidos, bem como de uma regra de tomada de decisão baseada na comunicação ocorrida. A questão fundamental dessa teoria é que tipo de decisão se deseja implantar com o mecanismo. No presente estudo, busca-se a teoria

4 Teixeira, F. STF começa a votar sequestro de renda. Valor Econômico, 28 mar/2008.

Est. Econ., São Paulo, vol. 42, n.4, p. 671-699, out.-dez. 2012 
de desenho de mecanismos para entender os incentivos com os quais se defrontam os agentes tomadores de decisão, governos estaduais e municipais e os credores de precatórios desses entes e, levando em conta esses incentivos e partindo da premissa de que todos tomam suas decisões de forma estratégica, construir regras para uma alocação ótima de recursos.

O estudo do tema aqui introduzido encontra-se dividido da seguinte maneira. Na segunda seção, tem-se um resumo da legislação dos precatórios, como vinha sendo aplicada, e as recentes alterações promovidas pela recente $\mathrm{EC} \mathrm{n}^{\mathrm{o}}$ 62, de 2009. A seção 3 traz evidências quantitativas sobre o estoque da dívida e algumas considerações básicas acerca do seu pagamento, com a nova legislação aprovada. A seção 4 analisa os incentivos com os quais os estados e municípios se defrontam quanto ao apoio à $\mathrm{EC} \mathrm{n}^{\mathrm{o}} 62$, mostrando que houve forte incentivo para que estados e municípios apoiassem a nova legislação. A seção 5 propõe um formato específico para os leilões de deságio de precatórios citados na legislação envolvendo uma generalização dos leilões de Vickrey, sendo derivado seu simples equilíbrio e determinado o benefício esperado para os estados e municípios com o deságio da dívida correspondente. A seção 6 chama a atenção para o importante papel desempenhado pelo Conselho Nacional de Justiça na regulação da $E C n^{\circ} 62$, de forma a fechar uma importante brecha deixada na redação inicial da emenda. Por fim, a seção 7 traz as considerações finais do trabalho.

\section{Precatórios e a Emenda Constitucional no 62}

Precatório judicial significa requisição de pagamento do montante da condenação judicial, feita pelo Presidente do Tribunal, em que a decisão objeto de execução contra a Fazenda (União, Estados-membros, DF e Municípios) foi proferida. O pagamento corre por conta de verba consignada na Lei Orçamentária Anual diretamente ao Poder Judiciário. A matéria está regulada no art. 100 da Constituição Federal.

O Presidente do Tribunal requisita o pagamento, expedindo o competente precatório judicial. Entregue esse precatório ao ente político devedor, este deverá incluí-lo na ordem cronológica para pagamento oportuno. Os precatórios entregues até $1^{\circ}$ de julho de cada ano de- 
vem ter seus valores incluídos na Lei Orçamentária Anual do exercício seguinte, para pagamento atualizado até o final desse exercício. Cabe enfatizar, no entanto, que a simples inclusão do crédito destinado ao pagamento do precatório no orçamento não significa que este vá efetivamente ser pago. Compete a esse mesmo Presidente ordenar o pagamento dentro da ordem cronológica e segundo as possibilidades de depósito. No caso de quebra dessa ordem, cabe o sequestro de rendas para o pagamento do credor preterido, se este assim o requerer.

Existem algumas consequências pelo descumprimento dos precatórios judiciais, como intervenção federal nos estados, responsabilização dos governantes ou rejeição das contas do Poder Executivo. No entanto, todos esses institutos, por nunca terem sido utilizados, não produziram efeito algum, nem mesmo como ameaça em potencial. A penalidade que mais tem assustado os administradores públicos é o sequestro de renda, possível somente no caso de preterição do direito de precedência do credor no caso dos precatórios não alimentares. ${ }^{5}$

O controle da ordem cronológica pertence ao ente devedor. Assim, a preterição acontecia no âmbito do Poder Executivo, e, conforme se discute em Oliveira (2005), pode ser decorrente da compensação de débito tributário com precatório, do parcelamento do precatório nos termos previstos no art. 78 do Ato das Disposições Constitucionais Transitórias - ADCT, ou de equivocada medida constante na elaboração de listagens de ordens cronológicas distintas por tribunal e não apenas em razão da natureza do crédito. Todas essas questões tentaram ser resolvidas pela $\mathrm{EC} \mathrm{n}^{\mathrm{o}} 62$, de 2009, por meio de um sistema através do qual, por um lado, os devedores (Estados e Municípios) comprometam uma parcela fixa e limitada de suas receitas com o pagamento de precatórios e, por outro, os credores recebam seus recursos mais prontamente, porém sujeito a um deságio no valor do crédito. Para tanto, a proposta estipula, em primeiro lugar, que os credores de precatórios, ao mesmo tempo, sejam devedores da mesma fazenda pública além de pagos através da compensação de débitos e créditos. Ou seja, protege-se o erário de ser obrigado a pagar, em dinheiro, uma dívida a uma pessoa que também lhe deve. Em segundo lugar, estabelece um mecanismo que, na prática, alguns estados já tentaram utilizar: o uso de precatórios (próprios ou de

5 Conforme decisão proferida pelo Supremo Tribunal Federal na ADI no ${ }^{\circ}$ 1662-SP.

Est. Econ., São Paulo, vol. 42, n.4, p. 671-699, out.-dez. 2012 
terceiros) para o pagamento de dívida ativa. Em terceiro lugar, veda a cobrança de "juros compensatórios", ${ }^{6}$ o que reduz a conta a ser paga pelos entes públicos.

Por fim, a legislação propõe a abertura de uma exceção ao atual regime de pagamento de precatórios por ordem de chegada. O caput do art. 97 do ADCT, introduzido pela Emenda Constitucional no 62/09, é claro ao dispor que os estados, o Distrito Federal e os municípios, que na data de publicação da Emenda Constitucional estivessem em mora na quitação de precatórios vencidos, farão seus pagamentos de acordo com normas especiais. Nesse caso, existem duas opções para os entes federativos. Na primeira, o ente público deve reservar uma parcela de recursos, que será depositada em conta especial, para o pagamento de precatórios. Tal conta será administrada pelo Tribunal de Justiça local. Os recursos dessa conta específica só sairão para pagamento de precatórios, o que dá aos credores uma maior garantia de recebimento. O montante mínimo a ser depositado pelos Estados equivale a $1,5 \%$ da receita corrente líquida (depósito mensal de 1/12 do valor anual), se a unidade da federação fosse das regiões Norte, Nordeste ou Centro-Oeste, ou de outra região se seu estoque de precatórios pendentes não exceder 35\% da receita corrente líquida. No entanto, se for um estado da Região Sul ou Sudeste, cujo estoque de precatórios exceda 35\%, então o percentual será de 2,0\%. A outra opção do ente federativo é adotar um regime especial, que pode durar até 15 anos, sendo que, nesse caso, o estado estará obrigado a depositar anualmente, em conta especial, o saldo total dos precatórios devidos, acrescido do índice oficial de remuneração básica da caderneta de poupança e de juros simples no mesmo percentual de juros incidentes sobre a caderneta de poupança para fins de compensação da mora, excluída a incidência de juros compensatórios, diminuído das amortizações e dividido pelo número de anos restantes no regime especial de pagamento. Também nessa opção, a conta especial criada para esse fim será administrada pelo Tribunal de Justiça local.

Em ambas as escolhas, pelo menos 50\% dos recursos serão utilizados para pagamento de precatórios em ordem cronológica. O restante dos depósitos deverá ser destinado aos precatórios por três meios,

${ }^{6}$ Havia a incidência de juros compensatórios de $12 \%$ ao ano sobre as indenizações por desapropriação, sejam elas feitas para projetos de infraestrutura, obras urbanas, criação de áreas de preservação ambiental ou reforma agrária. Apesar de nunca terem sido fixados em lei, os juros compensatórios estavam previstos, desde 1984, pela Súmula no 618 do Supremo Tribunal Federal. 
isolados ou simultaneamente. São eles: I - leilão; II - pagamento à vista de precatórios por ordem crescente de valor; III - pagamento por acordo direto com os credores, conforme lei própria da entidade devedora, admitindo-se a existência de câmara de conciliação.

Os entes públicos que optassem pelo regime especial não ficariam sujeitos ao sequestro de recursos por determinação judicial, a menos que não cumprissem os termos desse regime. O "regime especial" cessaria quando o montante de precatórios a pagar fosse menor do que o montante de recursos reservado para tal na conta especial acima citada ou ao final do prazo de quinze anos. Nesse momento, a unidade da federação retornaria ao sistema de pagamento por ordem cronológica de chegada dos precatórios, conforme dispõe o art. 100 da Constituição Federal.

Assim, entre os diversos aspectos meritórios da EC no 62, de 2009, pode-se citar a possibilidade de solução de um conflito no qual todas as partes encontravam-se em posição de desvantagem. Ao se instituir o sistema de leilões, com recursos previamente fixados e separados para o pagamento dos precatórios, acelera-se o ritmo de pagamento das dívidas judiciais: ganham os credores, que receberão mais prontamente seus direitos; ganham os entes públicos, que não correrão o risco de ter uma parcela crescente de suas receitas comprometidas com o pagamento dos precatórios; e ganha a sociedade, que não corre o risco de ter serviços públicos essenciais interrompidos em função de bloqueio judicial das contas dos entes públicos. Também é benéfica a redução de pontos de atrito entre o Poder Judiciário (que manda pagar) e o Poder Executivo (que não pagava ou pagava a menor), contribuindo para a consolidação das instituições republicanas.

Não obstante as vantagens apontadas, a proposta padece de alguns incentivos negativos. O primeiro deles é o estímulo à criação de novos precatórios. Se o erário fica autorizado a leiloar o pagamento de precatórios, obtendo desconto nos valores a pagar, haverá o estímulo a não pagar as despesas da administração, para que estas virem precatórios e venham a ser pagas, no futuro, com desconto. As vantagens seriam duas: ganhar-se-ia prazo para o pagamento de uma obrigação e esta seria quitada com desconto. 
Há, na legislação, outro mecanismo que tende a estimular o não pagamento de despesas e a criação de novos precatórios. A lei estabelece que o "regime especial" cessará quando o estoque de precatórios a pagar for inferior ao montante de recursos reservados para tal $(1,5 \%$ ou $2 \%$ da receita corrente líquida). Se a opção por fazer os depósitos mensais na conta especial for benéfico para a administração pública, esta tentará evitar o seu fim. Sempre que o montante de precatórios a pagar estiver chegando ao limite que determina o fim da primeira opção do regime especial, a administração terá incentivos para acumular novos precatórios, para que o regime seja mantido.

Finalmente, a EC $\mathrm{n}^{\mathrm{o}} 62$ criou incentivos para que os estados e municípios não descumpram as regras relativas ao regime que aderiram, quais sejam: I - sequestro de quantia nas contas de estados, Distrito Federal e municípios devedores, por ordem do Presidente do Tribunal; II - o credor terá automaticamente poder liberatório do pagamento de tributos de estados, Distrito Federal e municípios devedores, até onde se compensarem; III - o chefe do Poder Executivo responderá na forma da legislação de responsabilidade fiscal e de improbidade administrativa; IV - enquanto perdurar o não cumprimento, a entidade devedora não poderá contrair empréstimo externo ou interno e ficará impedida de receber transferências voluntárias; V - a União reterá os repasses relativos ao Fundo de Participação dos Estados e do Distrito Federal e ao Fundo de Participação dos Municípios, e os depositará nas contas especiais, sempre que o ente quebrar o pacto.

A próxima seção apresenta alguns dados que retratam a situação dos estados, comparando o estoque de precatórios com os valores da receita corrente líquida e os desembolsos aproximados que os estados terão que fazer caso optem pela primeira ou pela segunda opção do regime especial, antes de se avaliar os benefícios adicionais associados aos leilões de deságio.

\section{Evidência Quantitativa}

A tabela a seguir mostra o estoque de precatórios de responsabilidade dos governos estaduais, conforme levantamento efetuado pelo STF até 2004, com atualização até 2007. Acrescentam-se a essa in- 
formação os dados da receita corrente líquida de cada estado em 2007 (fornecidos pela Secretaria do Tesouro Nacional), conforme o cálculo explicado na EC nº 62, de 2009.

Note que a Tabela I traz informações para as duas opções de regime especial previstas na $E C n^{0}$ 62, de 2009. No caso da opção 1, em que o estado faz um depósito mensal equivalente a um percentual de sua receita corrente líquida, calcula-se o tempo necessário para quitação do estoque de precatórios. O percentual aplicado (coluna B) é de 1,5\% para todos os estados, exceto Espírito Santo e Paraná, onde se aplicam $2 \%$. Isso ocorreu porque esses são os dois únicos estados das regióes Sul e Sudeste cujo valor da dívida em precatórios excede $35 \%$ da receita líquida. Em vez de se fazer o cálculo mensal, como determina a lei, calcula-se uma aproximação do desembolso anual com base na receita corrente líquida anual de cada estado no exercício de 2007.

O pior caso reside no Mato Grosso, onde seriam necessários mais de 55 anos para que a dívida com precatórios judiciais fosse quitada. No entanto, no geral, as regras impõem um tempo bem razoável, pois a média de quitação dos valores, entre todos os estados, é de 9,5 anos. Note que essa estimativa do tempo para quitação tende a ser maior se for incluído um fluxo de novos precatórios contribuindo para fazer crescer o montante da dívida. No entanto, os cálculos refletem o tempo necessário para a quitação da dívida atual. Por outro lado, os leilões de deságio previstos na nova legislação tendem a reduzir esse tempo. Na seção 5 , será apresentada nova estimativa, considerando a possibilidade de o estado pagar sua dívida com deságio.

Relativamente à segunda opção de regime especial, calcula-se o valor estimado do desembolso anual. No primeiro ano, esse valor é igual ao estoque da dívida dividido por quinze, tempo em anos estabelecido pela EC no 62, de 2009. Perceba que o Estado tenderá a escolher o regime especial que lhe gere um menor desembolso anual. Comparando as colunas D e F, tenderão a escolher a opção 1 apenas o Distrito Federal, o Espírito Santo, o Mato Grosso e o Paraná, ou seja, aqueles estados cujo tempo necessário para quitação pela opção $l$ é maior do que quinze anos. 


\section{Tabela I}

\begin{tabular}{|c|c|c|c|c|c|c|}
\hline \multirow[b]{2}{*}{ Estado } & \multirow[b]{2}{*}{$\begin{array}{l}\text { Dívida com } \\
\text { precatórios } \\
(1,2) \\
\mathrm{R} \$ \text { mil } \\
\text { (A) }\end{array}$} & \multicolumn{4}{|c|}{ Regime Especial: Opção 1} & \multirow{2}{*}{$\begin{array}{l}\text { Regime Especial: Opção } 2 \\
\text { Desembolso anual } \\
\text { R\$ mil } \\
(F)=(A) / 15\end{array}$} \\
\hline & & $\begin{array}{l}\text { Percentual } \\
\text { aplicado no } \\
\text { estado } \\
\text { (B) }\end{array}$ & $\begin{array}{l}\text { Receita } \\
\text { Corrente } \\
\text { Líquida (3) } \\
\text { R\$ mil } \\
\text { (C) }\end{array}$ & $\begin{array}{c}\begin{array}{c}\text { Desembolso } \\
\text { anual }\end{array} \\
\mathrm{R} \$ \text { mil } \\
(\mathrm{D})=(\mathrm{B}) \times(\mathrm{C})\end{array}$ & $\begin{array}{c}\text { Tempo } \\
\text { necessário } \\
\text { para quitação } \\
\text { Anos } \\
(E)=(A) /(D)\end{array}$ & \\
\hline$A C$ & 170.039 & $1,5 \%$ & 2.304 .712 & 34.571 & 4,9 & 11.336 \\
\hline$A L$ & 354.924 & $1,5 \%$ & 4.106 .624 & 61.599 & 5,8 & 23.662 \\
\hline AM & 56.278 & $1,5 \%$ & 6.913 .693 & 103.705 & 0,5 & 3.752 \\
\hline AP & 71.811 & $1,5 \%$ & 2.289.789 & 34.347 & 2,1 & 4.787 \\
\hline$B A$ & 1.779 .109 & $1,5 \%$ & 17.499 .662 & 262.495 & 6,8 & 118.607 \\
\hline CE & 49.788 & $1,5 \%$ & 9.178 .633 & 137.679 & 0,4 & 3.319 \\
\hline DF & 3.312 .815 & $1,5 \%$ & 9.341 .719 & 140.126 & 23,6 & 220.854 \\
\hline ES & 9.598 .541 & $2,0 \%$ & 9.569 .420 & 191.388 & 50,2 & 639.903 \\
\hline GO & 1.316 .900 & $1,5 \%$ & 10.149 .596 & 152.244 & 8,6 & 87.793 \\
\hline MA & 106.026 & $1,5 \%$ & 6.249 .116 & 93.737 & 1,1 & 7.068 \\
\hline$M G$ & 2.240 .877 & $1,5 \%$ & 34.340 .126 & 515.102 & 4,4 & 149.392 \\
\hline MS & 421.984 & $1,5 \%$ & 5.555 .718 & 83.336 & 5,1 & 28.132 \\
\hline MT & 5.857 .463 & $1,5 \%$ & 6.981 .897 & 104.728 & 55,9 & 390.498 \\
\hline PA & 11.840 & $1,5 \%$ & 8.315 .613 & 124.734 & 0,1 & 789 \\
\hline PB & 190.954 & $1,5 \%$ & 5.067 .245 & 76.009 & 2,5 & 12.730 \\
\hline PE & 131.852 & $1,5 \%$ & 11.226 .479 & 168.397 & 0,8 & 8.790 \\
\hline $\mathrm{PI}$ & 189.827 & $1,5 \%$ & 3.578 .711 & 53.681 & 3,5 & 12.655 \\
\hline PR & 14.126 .925 & $2,0 \%$ & 17.387 .982 & 347.760 & 40,6 & 941.795 \\
\hline RJ & 1.884 .635 & $1,5 \%$ & 34.576 .813 & 518.652 & 3,6 & 125.642 \\
\hline $\mathrm{RN}$ & 155.473 & $1,5 \%$ & 5.181 .987 & 77.730 & 2,0 & 10.365 \\
\hline RO & 492.726 & $1,5 \%$ & 3.414 .203 & 51.213 & 9,6 & 32.848 \\
\hline $\mathrm{RR}$ & 2.683 & $1,5 \%$ & 1.609 .335 & 24.140 & 0,1 & 179 \\
\hline RS & 2.999 .154 & $1,5 \%$ & 20.570 .967 & 308.565 & 9,7 & 199.944 \\
\hline SC & 322.966 & $1,5 \%$ & 9.636 .882 & 144.553 & 2,2 & 21.531 \\
\hline SE & 101.598 & $1,5 \%$ & 4.000 .527 & 60.008 & 1,7 & 6.773 \\
\hline SP & 13.017 .305 & $1,5 \%$ & 91.760 .332 & 1.376 .405 & 9,5 & 867.820 \\
\hline TO & 17.380 & $1,5 \%$ & 3.440 .015 & 51.600 & 0,3 & 1.159 \\
\hline
\end{tabular}

Fonte: Dívida com precatórios - Supremo Tribunal Federal.

Receita Corrente Líquida - Balanço Estadual de 2007/Secretaria do Tesouro Nacional.

Nota: 1- Valores dos precatórios com base em levantamento até dezembro de 2004, atualizados pelo STF até dezembro de 2007.

2 - O levantamento não considera os ingressos de precatórios de 2005 a 2007.

3 - Relativo ao exercício de 2007. 


\section{A Restrição de Participação dos Estados e Municípios}

O primeiro desafio deste artigo é modelar as alterações fundamentais advindas da EC n ${ }^{\circ} 62$, de 2009, de forma a entender por que, por um lado, uma emenda dessa natureza não foi aprovada antes e, por outro lado, por que ela recebeu apoio no Congresso em 2009.

De forma a simplificar a discussão, usaremos no que se segue o termo genérico "estado" para representar a unidade da federação que será afetada pela regra proposta, seja ela um estado ou um município. O estado (seu governador ou prefeito) deriva utilidade do gasto público. Por simplicidade, existe um único período e o estado dispõe de um orçamento $F$ que deve ser usado para financiar o gasto público e pagar sua dívida em precatórios $P$ no período, sendo $P<F$. O estado possui uma função de utilidade $u$ estritamente crescente - no gasto público - e côncava, podendo ser linear, ou seja, o Estado pode ser avesso ou neutro em relação ao risco.

\subsection{Ambiente Institucional Anterior à Emenda: O Mecanismo Estocástico}

O estado deve decidir se usa parte de seu orçamento $F$ para pagar os precatórios em montante $P$, ou se tenta não pagar essa dívida. Caso decida pagar a dívida, sua utilidade resultante será $U_{a}(F, P ; s)=u(F-P)$, em que o índice $a$ refere-se à situação anterior à emenda e o argumento $s$ explicita a decisão de pagar (sim).

Caso decida não pagar a dívida, há uma probabilidade $\pi$ de a Justiça ordenar o sequestro de recursos do estado, forçando o pagamento dos precatórios. Portanto, resta a probabilidade $1-\pi$ dos recursos não serem sequestrados e o estado poder usar a integralidade de seu orçamento para financiar o gasto público. Independentemente do resultado da Justiça, a decisão de não honrar sua dívida implica uma perda de reputação do estado que é parametrizada aqui pelo custo $r>0$ em sua função de utilidade.

Destarte, caso decida não pagar a dívida, sua utilidade será $U_{a}(F, P ; n)=\pi u(F-P)+(1-\pi) u(F)-r$, em que o argumento $n$ refere-se à decisão do estado de não pagar sua dívida. 
Portanto, o estado decidirá pelo não pagamento dos precatórios se $U_{a}(F, P ; s)>U_{a}(F, P ; n)$, o que pode ser reescrito segundo a expressão abaixo.

$$
(1-\pi)(u(F)-u(F-P))>r
$$

O termo à esquerda da desigualdade (1) representa o benefício líquido do não pagamento dos precatórios $(u(F)-u(F-P))$, que ocorre somente com probabilidade $1-\pi$. Já o termo $r$ à direita representa a perda reputacional com a tentativa de calote. Vale observar que quanto maior for o valor da dívida, quanto mais sensível for o estado ao gasto público (quanto maior for a derivada de $u$ ) e quanto menor for a probabilidade de a Justiça sequestrar recursos do estado para o pagamento de precatórios, maior será o incentivo que o estado terá de não pagar a dívida. Por outro lado, quanto maior for o custo reputacional do não pagamento, menor será esse incentivo.

Argumentamos aqui que, no início do século, os parâmetros institucionais encontravam-se compatíveis com a desigualdade (1), o que explicaria o equilíbrio em que os estados não pagavam suas dívidas em precatórios, sem haver grande repercussão no Congresso.

É importante ressaltar que o modelo representa um caso extremo em que, ou o estado paga todos os precatórios devidos, no período segundo a regra institucional vigente, ou não paga nada. Naturalmente, a realidade corresponde a uma situação intermediária em que há pagamento parcial, não integral, nem nulo. Essa modelagem foi escolhida para explicar os principais incentivos, considerando-se o quadro institucional anterior à emenda de forma simples e concisa. O resultado aqui obtido se estende canonicamente para uma situação intermediária, em que existem mais opções para o estado decidir quanto a que percentual dos precatórios devidos ele escolherá pagar.

Considere agora as mudanças institucionais ocorridas ao longo da primeira década deste século. Em primeiro lugar, os riscos de sequestro de recursos dos estados aumentou, conforme discutido anteriormente, o que corresponde a um aumento no valor do parâmetro $\pi$ no modelo. Por outro lado, a sociedade se mobilizou no sentido de cobrar do estado o pagamento do precatório, o que corresponde a 
um aumento no valor do parâmetro $r$. Finalmente, deve-se lembrar que a consolidação da nova legislação eleitoral com a possibilidade de reeleição também tornou o titular candidato mais sensível às demandas da sociedade, o que também se traduz num aumento do parâmetro $r$. Tais mudanças possivelmente reduziram o lado esquerdo da Expressão (1) e aumentaram seu lado direito, fazendo com que os estados buscassem no Congresso alternativas institucionais que evitassem o pagamento integral dos precatórios. ${ }^{7}$ A próxima seção analisa a solução encontrada.

\subsection{Ambiente Institucional Posterior à Emenda: O Mecanismo quase Determinístico}

Após a promulgação da emenda constitucional EC $\mathrm{n}^{\mathrm{0}}$ 62, o estado fica obrigado a pagar a dívida $P$, devida no período, não havendo, portanto, a possibilidade de não pagamento, nem o custo reputacional da tentativa de calote, $r$. No entanto, como será aplicado mecanismo de deságio em parte dessa dívida, o valor final a ser desembolsado pelo estado será menor que $P$. Seja $F-d P$ o equivalente certeza da loteria associada ao mecanismo de deságio no novo ambiente institucional, em que, naturalmente, $0<d<1$. Então, a utilidade do estado no novo ambiente institucional é dada por $U_{p}(F, P ; d)=u(F-d P)$, em que o índice $p$ refere-se ao ambiente institucional posterior à emenda. Caso a emenda não seja aprovada no Congresso, admitindo que haja também incentivo ao não pagamento, ainda que menor, no ambiente anterior, ${ }^{8}$ a utilidade o estado será $U_{a}(F, P ; n)$. Portanto, o estado apoiará a emenda se $U_{p}(F, P ; d)>U_{a}(F, P ; n)$, o que pode ser reescrito segundo a expressão abaixo:

$\pi(u(F-d P)-u(F-P))>(1-\pi)(u(F)-u(F-d P))-r$

O lado esquerdo da Expressão (2) representa o benefício do novo mecanismo de pagamento da dívida em comparação ao anterior $(u(F-d P)-u(F-P))$, que é realizado quando, no mecanismo an-

\footnotetext{
7 Os autores agradecem as contribuições de dois pareceristas anônimos que sugeriram grande parte das alterações incluídas na versão atual do modelo, inclusive a probabilidade de não pagamento e o papel da reeleição. As responsabilidades pelos erros e imprecisões, no entanto, permanecem sendo dos autores.

8 A análise do caso em que há incentivo ao pagamento no ambiente anterior é trivial e é deixada ao leitor como exercício.
} 
terior, o estado é forçado a pagar a dívida (o que ocorre com probabilidade $\pi$ ). Já o lado direito representa o benefício da permanência no ambiente anterior $(u(F)-u(F-d P))$, que é realizado apenas quando o estado não é obrigado a pagar sua dívida (o que ocorre com probabilidade $(1-\pi)$ ), descontado o custo reputacional $r$.

É importante observar que quanto maior for o deságio da dívida, quanto mais sensível for o estado ao gasto público (quanto maior for a derivada de $u$ ), quanto maior for a probabilidade da Justiça sequestrar recursos do estado para o pagamento de precatórios e quanto maior for o custo reputacional da tentativa de calote, mais atraente será o novo mecanismo para o estado. Conforme discutido no final da seção anterior, a maior probabilidade de sequestro de bens do estado e o maior custo reputacional do calote, agregados ao benefício adicional da redução da dívida via deságio, sugerem que ao longo da primeira década do século o estado passou de uma situação em que a desigualdade (1) era satisfeita sem que a (2) o fosse, para uma situação em que a desigualdade (2) passou a ser satisfeita, ocasionando amplo apoio à EC no 62 em 2009.

Importante também é ressaltar o papel do deságio da dívida na decisão do estado em apoiar a emenda, o que sugere uma atenção maior a esse aspecto do novo ambiente institucional. A próxima seção tem por objetivo analisar cuidadosamente os incentivos com os quais se defrontam os credores de um estado que tenha aderido ao novo mecanismo, no que diz respeito à sua participação num leilão de deságio específico aqui proposto, com vistas a estimar o impacto do mecanismo determinístico na redução da dívida dos entes federativos.

\section{Leilões de Deságio de Precatórios e o Comportamento dos Credores}

Conforme visto anteriormente, a legislação prevê que até $50 \%$ dos recursos destinados ao pagamento de precatórios a cada ano sejam distribuídos por meio de leilões de deságio. Com vistas a analisar o novo mecanismo sob o ponto de vista dos credores, faz-se necessário apresentar uma proposta de formato para esses leilóes, o que constitui a principal contribuição desta seção. 


\subsection{Uma Proposta de Leilão de Deságio de Precatórios}

O mecanismo proposto consiste de um leilão selado do tipo de Vickrey (segundo preço) generalizado em que é leiloado, a cada um de dois períodos, o valor $m=\frac{50}{100} P$, em que $P$ é o montante de recursos reservado para pagamento de precatórios em cada período, segundo a $E C n^{\circ} 62$. O leilão proposto funciona da seguinte forma: cada participante $i$ apresenta um envelope selado contendo o fator de deságio $d_{i} \in[0,1]$ aceito para receber imediatamente seu crédito devido; portanto, se o crédito do participante $i$ é de $c_{i}$, então ele aceita receber imediatamente o valor $d_{i} c_{i}$ como quitação completa de sua dívida, configurando-se assim um deságio de dívida de $\left(1-d_{i}\right) c_{i}$. O participante $i$ possui utilidade $u$ definida sobre o montante líquido de crédito recebido do estado. Para simplificar a notação, ordene os lances $d_{i}$ em ordem crescente, renomeando os participantes, sem perda de generalidade, de forma que $d_{1} \leq d_{2} \leq \ldots \leq d_{n}$ em que $n$ é o número total de participantes. O número de vencedores será o maior número inteiro $k$ satisfazendo a desigualdade $d_{k+1}\left(c_{1}+c_{2}+\cdots+c_{k}\right) \leq m$.

Cada um dos $k$ vencedores será pago de acordo com o fator de deságio escolhido pelo jogador $k+1$, o primeiro perdedor. Caso se verifique empate, com dois credores oferecendo o mesmo fator de deságio, sendo que não há recurso suficiente para que os dois sejam vencedores, então será considerado primeiramente aquele que tiver o menor volume de dívida a receber, de forma a manter o princípio de prioridade ao pagamento das menores dívidas que permeia a nova legislação. Em caso de novo empate, então será escolhido vencedor um dos empatados de forma aleatória. Portanto, no leilão proposto, vencem os $k$ credores que aceitarem os maiores deságios (os menores valores de $d_{\mathrm{i}}$ ), sendo eles pagos de acordo com o $k+1$-ésimo maior deságio, tendo o valor de $k$ sido endogenamente determinado pela quantidade de recursos disponível para pagamento, $m$.

\subsection{O Comportamento dos Credores}

Defrontado com o novo mecanismo, o credor do estado tem duas opções: participar do leilão de deságio ou aguardar para receber seu crédito sem deságio. Como no último período toda a dívida do esta- 
do é saldada, não há interesse do credor em participar de nenhum leilão de deságio nesse período. Portanto, haverá leilões de deságio apenas nos períodos iniciais, o que, em nosso modelo simples, corresponde ao período 1 .

No primeiro período, o credor $i$ estima que, caso não participe do leilão, receberá seu crédito nesse período com probabilidade $\pi_{i} \in(0,1)$. Portanto, receberá esse crédito no segundo período com probabilidade $1-\pi_{i}$. Essa probabilidade depende das características específicas do credor. Por exemplo, como os $50 \%$ restantes do total de recursos a serem pagos no primeiro período é ordenado cronologicamente, se o credor tiver um crédito antigo, então $\pi_{i}$ será maior do que se ele tiver um crédito mais recente.

Dado o valor estimado de $\pi_{i}$, o credor poderá avaliar sua utilidade esperada caso não participe do leilão, qual seja,

$U_{i}\left(\pi_{i}, \delta_{i}, c_{i}\right)=\pi_{i} u\left(c_{i}\right)+\left(1-\pi_{i}\right) \delta_{i} u\left(c_{i}\right)=\left[1-\left(1-\delta_{i}\right)\left(1-\pi_{i}\right)\right] u\left(c_{i}\right)$

O parâmetro $c_{i}$ na Expressão (3) corresponde à dívida em precatórios em posse do credor $i$, conforme definido anteriormente. Já o parâmetro $\delta_{i}$ corresponde ao fator de desconto intertemporal específico desse credor. Esse fator reflete basicamente o custo de oportunidade para o credor $i$ de esperar mais um período até receber seu recurso e pode, naturalmente, variar de indivíduo a indivíduo. ${ }^{9}$

Observe que $r_{i}=1-\left(1-\delta_{i}\right)\left(1-\pi_{i}\right)<1$, ou seja, a demora esperada no pagamento gera um custo para o credor, que se reflete na redução de sua utilidade pelo fator $r_{i}$. Seja $\underline{c}_{i}$ o montante que, se pago ao credor imediatamente, o torna indiferente entre receber esse montante e não participar do leilão, ou seja, $u\left(c_{i}\right)=r_{i} u\left(c_{i}\right)=\left[1-\left(1-\delta_{i}\right)\left(1-\pi_{i}\right)\right] u\left(c_{i}\right)$,ou ainda, $\underline{c}_{i}=u^{-1}\left(\left[1-\left(1-\delta_{i}\right)\left(1-\pi_{i}\right)\right] u\left(c_{i}\right)\right)$. A Figura 1 a seguir apresenta esse valor graficamente, refletindo a restrição de participação do credor no leilão. Então, o credor aceitaria participar do leilão se dele recebesse pelo menos $\underline{c}_{i}$. Expressando o mesmo cálculo por meio do fator de deságio, o titular do precatório estaria disposto a participar do leilão se o fator de deságio pago para receber imediatamente seu crédito não for menor que $d_{i}=\frac{\underline{c}_{i}}{c_{i}}$.

9 No caso particular em que esse fator é constante tem-se $\delta_{i}=\delta$ para todos os credores. 
Dado que existe uma perda com a espera, e dadas as regras do leilão proposto, qualquer credor pode garantir que não será obrigado a incorrer em deságio maior que seu lance, todos os credores têm interesse em participar do leilão. Basta, para isso, que o credor $i$ escolha um lance maior ou igual a $d_{i}=\frac{c_{i}}{c_{i}}$. Em outras palavras, o leilão é individualmente racional também para os credores. Na próxima seção é calculado o equilíbrio de Nash em estratégias (fracamente) dominantes desse jogo, e é determinada uma estimativa para a economia feita pelo estado com o leilão.

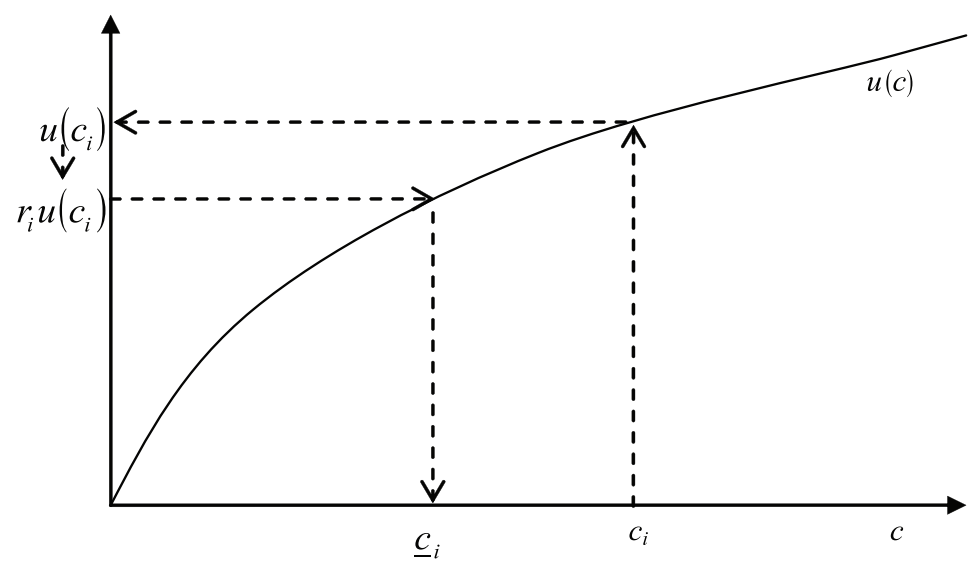

Figura 1 - Restrição de participação do credor no leilão

\subsection{O Equilíbrio de Nash do Leilão de Vickrey Generalizado}

Considerando que não há custo direto para entrada no leilão, e que, por meio de seu lance, qualquer participante pode garantir que não lhe será imposto fator de deságio menor que o mínimo que lhe é aceitável, todos os credores terão interesse em participar do leilão. Uma vez partícipe, o credor deve decidir que fator de deságio lançar. Mostraremos a seguir que é uma estratégia fracamente dominante para cada jogador $i$ escolher seu fator de deságio $d_{i}$. De fato, suponha que o credor tenha lançado $d_{i}$ e não tenha sido contemplado. Então o fator de deságio aplicado aos vitoriosos, digamos $\bar{d}$, ainda é menor ou igual ao seu. O que ele poderia ter feito? Se aumentasse o valor de seu fator de deságio $d_{i}$ nada mudaria, pois continuaria perdedor. 
Se o reduzisse, a ponto de fazer alguma diferença, teria que reduzi-lo abaixo do valor $\bar{d}$, mas então, como $\bar{d} \leq d_{i}$, ele receberia seu crédito com um deságio abaixo do mínimo aceitável, o que seria, para ele, pior que perder. Portanto, se ele está perdendo lançando seu fator de deságio $d_{i}$, não há nenhuma outra escolha que melhore sua utilidade esperada.

Suponha agora que o jogador tenha lançado $d_{i}$ e tenha sido contemplado. Então o fator de deságio aplicado $\bar{d}$ será maior ou igual a $d_{i}$. Mas então, se diminuísse seu fator de deságio, continuaria contemplado e isso não afetaria o deságio que lhe será aplicado. Por outro lado, se aumentar seu lance, poderá sair da categoria de vencedor, o que lhe é prejudicial se $\bar{d}>d_{i}$. Portanto, o credor não consegue ter benefício algum mudando sua estratégia. Destarte, lançar exatamente seu fator de deságio é uma estratégia fracamente dominante para cada credor. Portanto, demonstramos a seguinte proposição:

Proposição 1. Considere o modelo de leilão de Vickrey generalizado de deságio de precatórios. Então, existe um equilíbrio de Nash em estratégias puras fracamente dominantes em que todo credor deseja participar e, além disso, cada participante i lança seu fator de deságio $d_{i}$.

\subsection{O Ganho Esperado para o Estado}

Qual será o ganho esperado para o estado nesse equilíbrio? Para calcular esse ganho, é necessário estimar as distribuições dos tipos dos credores, ou seja, as distribuições dos valores $d_{i}$. Suponha, portanto, que, para cada credor $i$, o deságio $d_{i}$ encontra-se uniformemente distribuído no intervalo $\left[d_{0}, 1\right]$, em que $d_{0}>0$ é o deságio mínimo possível. Nas simulações efetuadas mais à frente será adotado o valor $d_{0}=0,5$, modelando o fato de que um credor aceitaria no máximo o deságio de $50 \%$ sobre o precatório devido.

O número de vencedores é definido endogenamente no leilão. Se os lances feitos pelos jogadores forem ordenados (sem perda de generalidade) em ordem crescente $\left(d_{1}, d_{2}, \ldots, d_{n}\right)$ em que $n$ é o número total de credores e $d_{1}<d_{2}<\ldots<d_{n}$, então o número de vencedores será o maior inteiro $k$ tal que $d_{k+1}\left(c_{1}+c_{2}+\cdots+c_{k}\right) \leq m$. Para simplificar os cálculos, suponha que todos os credores são portadores do 
mesmo montante de precatórios, ou seja, $c_{i}=c, \forall i=1, \ldots, n$. Então o número de vencedores será o maior inteiro $k$ tal que $k d_{k+1} \leq \frac{m}{c}$.

A proposição a seguir apresenta o ganho médio esperado do estado com o leilão quando há exatamente $n$ credores participando do leilão, sendo $k$ o número de vencedores:

Proposição 2. Considere o leilão de Vickrey generalizado para o deságio de precatórios em que há n credores participando do leilão. Suponha que o fator de deságio mínimo de cada credor se encontra uniformemente distribuído no intervalo $\left[d_{0}, 1\right] \subset[0,1]$ e que cada credor detém o mesmo montante de precatório c. Suponha ainda que k credores vencem o leilão. Então o ganho esperado por credor vencedor para o estado (o leiloeiro) é dado por:

$$
\frac{n-k}{n+1}\left(1-d_{0}\right) c
$$

Prova: Calculemos em primeiro lugar o ganho esperado do leiloeiro dividido pelo número de vencedores, $k$, quando o jogador 1 é o primeiro vencedor (fez o menor lance $d_{1}$ ), o jogador 2 é o segundo vencedor (fez o segundo menor lance $d_{2}$ ) e assim sucessivamente até o jogador $k$, que é o último vencedor; o jogador $k+1$ é o primeiro perdedor, sendo seu lance $d_{k+1}$ o deságio usado no cálculo do pagamento aos credores; os demais $n-(k+1)$ jogadores são os perdedores com lances acima de $d_{k+1}$. Lembrando que a distribuição uniforme no intervalo $\left[d_{0}, 1\right]$ tem função densidade de probabilidade constante dada por $f(d)=\frac{1}{1-d_{0}}$, e que o estado (leiloeiro) economiza um montante de $\left(1-d_{k+1}\right) c$ para cada pagamento feito com o deságio $d_{k+1}$, pode-se expressar o ganho esperado por vencedor para o leiloeiro na forma a seguir.

$$
\int_{d_{0}}^{1} \int_{d_{1}}^{1} \int_{d_{2}}^{1} \cdots \int_{d_{k-1}}^{1} \int_{d_{k}}^{1} \int_{d_{k+1}}^{1} \int_{d_{k+1}}^{1} \cdots \int_{d_{k+1}}^{1} \int_{d_{k+1}}^{1}\left(1-d_{k+1}\right) c\left(\frac{1}{1-d_{0}}\right)^{n} d d_{n} d d_{n-1} \cdots d d_{k+2} d d_{k+1} d d_{k} \cdots d d_{2} d d_{1}
$$

As primeiras $k$ operações de integração se referem aos $k$ vencedores. A operação seguinte diz respeito ao primeiro perdedor, cujo lance determina o deságio usado no pagamento dos vitoriosos. Finalmente, 
as últimas $n-(k+1)$ operações se referem aos demais perdedores. Essa integral múltipla é calculada abaixo.

$$
\begin{aligned}
& c\left(\frac{1}{1-d_{0}}\right)^{n} \int_{d_{0}}^{1} \int_{d_{1}}^{1} \int_{d_{2}}^{1} \cdots \int_{d_{k-1}}^{1} \int_{d_{k}}^{1}\left(1-d_{k+1}\right)^{n-k} d d_{k+1} d d_{k} \cdots d d_{2} d d_{1} \\
& =c\left(\frac{1}{1-d_{0}}\right)^{n} \int_{d_{0} d_{1} d_{2}}^{1} \int_{d_{k-1}}^{1} \cdots \int_{d_{k-1}}^{1} \frac{\left(1-d_{k+1}\right)^{n-k+1}}{n-k+1} d d_{k} \cdots d d_{2} d d_{1}=c\left(\frac{1}{1-d_{0}}\right)^{n} \frac{\left(1-d_{0}\right)^{n+1}}{(n+1) n \cdots(n-k+1)} \\
& \frac{(n-k) !}{(n+1) !}\left(1-d_{0}\right) c
\end{aligned}
$$

O retorno esperado acima foi calculado para uma possível configuração da ordem dos vencedores e do primeiro perdedor: $1,2,3, \ldots, k$ para os vencedores, $k+1$ para o primeiro perdedor. Para considerar todas as possíveis configurações da ordem dos vencedores e do primeiro perdedor, temos que multiplicar esse número por $n$ (possíveis primeiros vencedores), $n-1$ (possíveis segundos vencedores, dada a seleção do primeiro vencedor),...., $n-(k-1)$ (possíveis $k$-ésimos vencedores, dadas as seleções dos vencedores anteriores), $n-k$ (possíveis primeiros perdedores, dadas as seleções dos vencedores). Portanto, o número acima deve ser multiplicado por:

$$
n(n-1) \cdots(n-k+1)(n-k)=\frac{n !}{(n-k-1) !} \text {, resultando na seguinte ex- }
$$

pressão para o retorno esperado para o leiloeiro, dividido pelo número de vencedores:

$$
\frac{n !}{(n-k-1) !} \frac{(n-k) !}{(n+1) !}\left(1-d_{0}\right) c=\frac{n-k}{n+1}\left(1-d_{0}\right) c .
$$

A Expressão (4) permite derivar importantes conclusões a respeito do papel dos diferentes parâmetros no retorno esperado médio (por vencedor) para o estado nesse leilão. Em primeiro lugar, nota-se o natural papel das necessidades de recursos dos credores, modelada pelo fator de deságio mínimo $d_{0}$ : quanto maior for esse parâmetro, mais pacientes serão os credores e, portanto, menos dispostos estarão a aceitar grandes deságios para receber logo o que lhes é devido. 
Então, maiores serão seus lances, e, consequentemente, menor será o retorno para o estado. Em segundo lugar, nota-se o importante papel do número de participantes do leilão, $n$. De fato, mantendo-se constante o número de vencedores, então a expressão se aproxima assintoticamente de $\left(1-d_{0}\right) c$ quando $n$ aumenta. Mas $\left(1-d_{0}\right)$ é o maior deságio que o estado pode conseguir, mesmo em uma situação de informação completa. Portanto, à medida que aumenta o número de participantes, ceteris paribus, aumenta também a receita esperada do leiloeiro, tendendo, no limite, ao maior deságio possível de precatórios. Esta propriedade mostra que o leilão proposto é extremamente benéfico para o estado quando há muitos credores. No entanto, espera-se que o leiloeiro dificilmente atinja esse retorno ótimo, uma vez que o número de participantes é finito. Na próxima seção são feitas simulações sobre o ganho esperado para o estado no equilíbrio de Nash encontrado nesse leilão, usando-se para tanto o limite acima encontrado $1-d_{0}$ e o deságio correspondente a um credor médio $1-E[d]=1-\frac{1+d_{0}}{2}=\frac{1}{2}\left(1-d_{0}\right)$.

\subsection{Simulação de Benefício para o Estado}

Como a EC n ${ }^{\circ} 62$, de 2009, prevê que até $50 \%$ do valor reservado pelo estado será para pagar os credores que participem de leilão em que terá preferência aquele que oferecer o maior deságio ao ente público, há a possibilidade do percentual médio do deságio ser significativo, de modo a acelerar a queda do estoque de precatórios. Com base na análise feita acima, se o fator de deságio mínimo aceitável pelo credor for $d_{0}=0,5$, então o maior fator de deságio que o estado pode conseguir é $1-d_{0}=0,5$. Isso ocorre no limite estudado anteriormente quando o número de participantes aumenta e o número de vencedores é mantido constante. Trata-se também do deságio máximo autorizado pelo CNJ em sua Resolução no 115 de 29 de junho de 2010, conforme será discutido na próxima seção. Por outro lado, o deságio médio esperado, ou seja, aquele aceito pelo credor médio, é dado por $1-E[d]=\frac{1}{2}\left(1-d_{0}\right)=0,25$. Nesta simulação consideram-se deságios médios de $50 \%$ e $25 \%$, a ser aplicado em $50 \%$ dos recursos depositados na conta especial, o que gera os valores retratados na Tabela II. 
Primeiramente, merece ser enfatizado que a reserva de valor destinada ao pagamento de precatórios corresponde à opção mais vantajosa para o estado. Como dito anteriormente, apenas o Distrito Federal, o Espírito Santo, o Mato Grosso e o Paraná escolherão a opção l. Note a queda do tempo necessário para quitação quando se considera o deságio. Quanto maior o deságio aplicado à dívida de precatórios, naturalmente maior a queda do tempo necessário para o fim de seu estoque, que acontece de forma acelerada, pois o valor reservado para o pagamento dos precatórios é ampliado, de forma análoga como ocorre com o multiplicador bancário no processo de criação de moeda. ${ }^{10}$ Para os quatro estados que escolherão a opção 1, o Distrito Federal, o Espírito Santo, o Mato Grosso e o Paraná, o tempo total necessário para o pagamento da dívida reduziu-se de aproximadamente 24, 50, 56 e 41 para aproximadamente 16, 34, 38 e 27 , respectivamente, correspondendo em uma redução de cerca de $33 \%$ na simulação mais otimista.

Cabe registrar que no segundo regime especial, em que o prazo é fixo em quinze anos, o deságio se refletirá em menores desembolsos anuais. Já no primeiro ano, por exemplo, são abatidos $10 \%$ da dívida, em vez de $6,67 \%$ (um quinze avos) caso não houvesse leilão de abatimento, na simulação mais otimista. Portanto, o desembolso no segundo período será de apenas $6 \%$ de dívida (atualizados monetariamente) e não mais de $6,67 \%$ como seria na ausência do leilão de abatimento. E assim o montante desembolsado irá se reduzindo sucessivamente a cada ano.

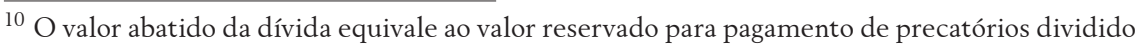
pelo fator de deságio $d$. 


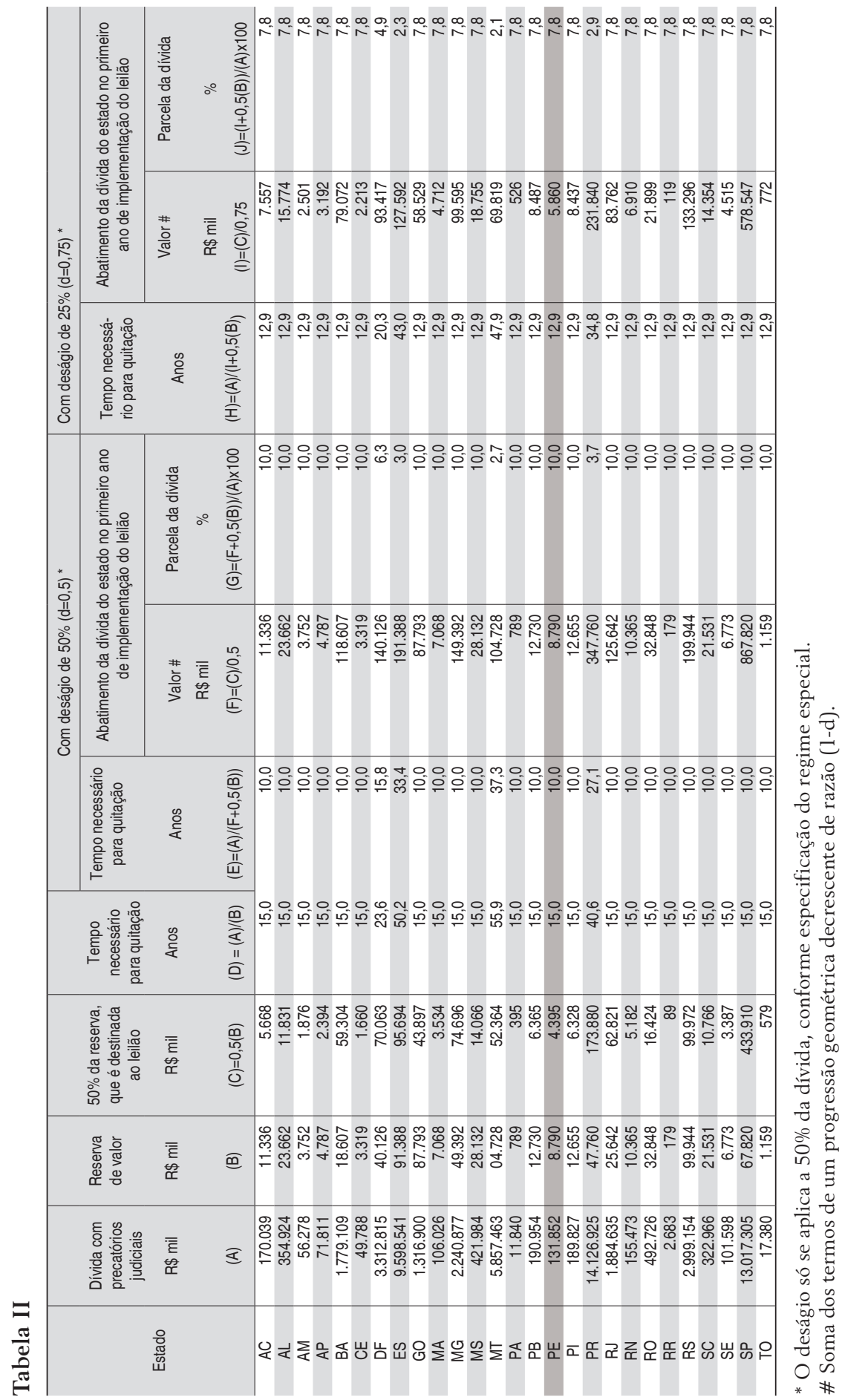


Infere-se das estimativas apresentadas que o leilão com base nos deságios é extremamente positivo para os estados. Basta saber que, tomando por base a dívida de todos eles, um deságio de $25 \%$ faz com que a dívida seja abatida em $2,9 \%$, quando o valor reservado para pagamento da dívida representa apenas $2,1 \%$ de seu total. Se o deságio for de $50 \%$, o abatimento é de $4,3 \%$, com a mesma reserva de recursos.

\section{O Conselho Nacional de Justiça Alinhando os Incentivos}

O Conselho Nacional de Justiça (CNJ), como orgão responsável pelo controle da atuação administrativa e financeira do Poder Judiciário, emitiu quatro resoluções a partir de outubro de 2009, regulando o funcionamento do sistema nacional de gestão de precatórios. São elas: Resolução $n^{\circ}$ 92, de 13 de outubro de 2009; Resolução $n^{\circ} 115$, de 29 de junho de 2010; Resolução $n^{\circ} 123$, de 9 de novembro de 2010; e a Resolução n ${ }^{\circ}$ 145, de 2 de março de 2012.

As quatro resoluções desempenham papel fundamental para ajustar os incentivos gerados pela $\mathrm{EC} \mathrm{n}^{\mathrm{o}} 62$, de forma a evitar o aproveitamento indevido de algumas brechas que por ventura fossem deixadas pela Emenda. A seguir discutimos brevemente as resoluções como forma de explicitar o importante papel do CNJ na implantação da EC n 62 .

A Resolução no 92, de 13 de outubro de 2009, precede a EC estabelecendo o Sistema de Gestão de Precatórios (SGP), com o objetivo de centralizar todas as informações disponíveis sobre a situação dos precatórios no país, bem como garantir o seu pagamento dentro das normas da lei. Essa resolução foi substituída pela Resolução $n^{0} 115$, em junho de 2010 e, portanto, vamos nos limitar a ressaltar que o SPJ ainda se encontra em implantação no presente momento, mas a resolução deixa clara a responsabilidade dos Tribunais em garantir o pagamento dos precatórios de acordo com a lei, inclusive lançando mão de intervenção nos estados e municípios inadimplentes, caso necessário.

Já a Resolução $n^{\circ} 115$, de 29 de junho de 2010, foi a primeira regulamentação da $E C n^{\circ} 62$. A resolução, além de reafirmar a implantação do SGP, também cria o cadastro de entidades devedoras 
inadimplentes, o CEDIN, no qual serão incluídas "as entidades devedoras que não realizarem a liberação tempestiva dos recursos [...]". Explicita ainda que as entidades listadas no CEDIN não poderão receber empréstimos, nem transferências voluntárias, nem mesmo via fundos constitucionais de participação dos estados e/ou municípios. Também regula a apresentação, expedição e compensação de precatórios, bem como sua requisição à entidade devedora. De forma mais fundamental, regula a gestão das contas especiais criadas pela EC $\mathrm{n}^{\circ}$ 62, a serem geridas pelos Tribunais de Justiça, requerendo a constituição de duas contas separadas, uma para o pagamento de precatórios segundo a ordem cronológica, outra para o pagamento segundo a nova modalidade que inclui os leilóes de deságio. Estabelece ainda a livre cessão de precatórios e, quanto ao leilão, estabelece limite máximo para o deságio de $50 \%$, ou seja, pelo menos $50 \%$ do valor dos precatórios deverá ser pago pela entidade devedora, deságio esse usado nos cálculos de nossas simulações.

Conforme vimos neste texto, vários estados, incluindo o Distrito Federal, o Espírito Santo, o Mato Grosso e o Paraná levariam bem mais que 15 anos para saldar suas dívidas em precatórios caso adotassem a opção de reserva de percentual fixo da receita líquida para seu pagamento, alguns chegando ao incrível prazo estimado de mais de 50 anos. Portanto, a Emenda estaria, de fato, legalizando a demora no pagamento, justificando a expressão de "emenda do calote" cunhada por alguns durante a fase de discussão no Congresso. A principal e fundamental contribuição da Resolução $\mathrm{n}^{\circ}$ 123, de 9 de novembro de 2010, foi fechar essa brecha ao exigir que os tribunais recalculem os percentuais de recursos a serem reservados ao pagamento de precatórios, aumentando-os se necessário, de forma que a totalidade dos precatórios, incluindo os novos, seja saldada em 15 anos, qualquer que seja o regime escolhido pela entidade devedora. Com relação ao formato do leilão, essa resolução estabelece um leilão discriminatório, ou seja, os vencedores serão aqueles que oferecerem maiores deságios, sendo que o deságio de cada vencedor será aquele por ele lançado no leilão. No entanto, a resolução prevê a possibilidade de formato distinto, desde que previsto no edital.

Finalmente, a Resolução $n^{\circ}$ 145, de 2 de março de 2012, estabelece juros de mora de $6 \%$ ao ano para dívidas vencidas anteriores à promulgação da emenda. 
Concluindo, o CNJ desempenhou papel fundamental para preservar o espírito da $\mathrm{EC} \mathrm{n}^{\circ} 62$, garantindo o pagamento da totalidade dos precatórios em 15 anos e fechando a inaceitável brecha que consistia na transferência do percentual mínimo de receita líquida exigida, o que poderia levar a um período superior a 50 anos para o pagamento integral da dívida. Além disso, o CNJ foi suficientemente flexível, permitindo a definição do modelo de leilão de deságio no ato do edital de convocação do leilão.

\section{Considerações Finais}

A inadimplência de vários estados e municípios brasileiros no pagamento de precatórios é de conhecimento público. Embora legítimo, por um lado, não é econômico, social, nem politicamente viável exigir a quitação imediata do total da dívida referente a precatórios. No entanto, também não havia como manter inalterada a recente situação, caracterizada por um embate entre os poderes Judiciário e Executivo prejudicial à consolidação das instituições no país.

A Emenda Constitucional $n^{\circ}$ 62, de 2009, foi aprovada devido a essa necessidade premente de mudança. A grande alteração constante dessa nova legislação consiste em permitir que os entes da federação, mediante a reserva obrigatória de recursos para pagamento de precatórios, adquiram a prerrogativa de estabelecer regime especial em que eles possam realizar leilões nos quais o credor que aceitar o maior desconto será o primeiro a receber seu pagamento.

A principal contribuição deste estudo foi demonstrar que as regras ali dispostas geram uma solução viável para a problemática dos precatórios. Para tanto, utilizou-se a Teoria de Desenho de Mecanismos para analisar o estabelecido na EC $n^{\circ} 62$, de 2009, mostrando ser essa emenda constitucional individualmente racional para os estados, uma condição que explica sua aprovação no Congresso. Cumprida essa etapa, o trabalho foi além da legislação citada, de forma a sugerir um formato específico para que os estados e municípios realizem seus leilões e, ainda, estimar os benefícios que esses leilões trarão aos estados e municípios.

Os principais resultados do estudo indicam que as unidades federativas tiveram, de fato, interesse em participar voluntariamente 
de um regime no qual elas sejam obrigadas a reservar parcela de seu orçamento, dado o cenário macroeconômico de taxas de juros suficientemente baixas. Tal cenário foi facilitado pelo ambiente de inflação reduzida, bem como pela maior pressão do Judiciário sobre as entidades inadimplentes, aumentando o risco de confisco de recursos. Tal ambiente nos permite melhor entender a aprovação da EC n 62 no Congresso Nacional em 2009.

Considerando que os leilóes sejam selados do tipo de Vickrey generalizado, demonstra-se que o credor terá interesse em participar do leilão, uma vez que não há risco para ele de incorrer em deságio superior ao seu lance. Mostra-se também que a estratégia (fracamente) dominante do credor é lançar o maior deságio que está disposto a assumir. Essa propriedade torna o leilão extremamente simples, não apenas do ponto de vista de implementação, mas também, e sobretudo, do ponto de vista do comportamento estratégico de cada participante, que não necessita se preocupar com as características dos demais participantes.

Quanto menos o credor estiver disposto a perder, mais paciente ele será, no sentido de poder esperar mais tempo para receber seu crédito. Essa situação gera menor deságio esperado para o ente federativo. Em contrapartida, quanto maior o número de participantes do leilão, maior é o deságio esperado para o ente público com o leilão, gerando resultados extremamente benéficos para os estados e municípios.

O presente estudo poderia ser expandido no sentido de incorporar funções de distribuição de probabilidade mais gerais para os participantes do leilão de forma a obter novas estimativas dos ganhos para os estados com o deságio. Poderia ainda analisar o equilíbrio que ocorreria no caso de um leilão discriminatório, em que a cada vencedor é aplicado o deságio por ele escolhido, de forma a comparar os dois possíveis modelos de leilões. Essas extensões são deixadas aqui como sugestão para pesquisas futuras. 


\section{Referências}

BARBOSA, D. B. Caminhos paralelos dos precatórios. Consulex - Informativo Jurídico, Brasília, ano XXI, no 12 , p. 16, mar/2007.

BATISTA, C. R. Utilização de precatórios para quitação de débitos tributários. Revista Dialética de Direito Tributário, $\mathrm{n}^{\circ}$ 129, p. 17-25, jun/2006.

BRASIL. Constituição (1988). Constituição da República Federativa do Brasil. Brasília, DF: Senado Federal, 2007.

ESTADÃO. PIB do Brasil fecha 2009 com retração de $0,2 \%$, a primeira queda anual em 17 anos. 11/3/2010. http://economia.estadao.com.br/noticias/economia,pib-do-brasil-fecha-2009-com-retracao-de-02-a-primeira-queda-anual-em-17-anos,8580,0.htm, acessado em 12/8/2012.

FLORENZANO, V. D. A Emenda Constitucional N.30, de 13.9.2000, sob a perspectiva da análise econômica do direito. In: VAZ, O. (Coord.). Precatórios: problemas e soluções. Belo Horizonte: Del Rey; Centro Jurídico Brasileiro, 2005.

HARADA, K. Precatório Judicial. Boletim de Direito Municipal, ano XXIII, nº 11, p. 809-818, nov/2007.

JACKSON, M. A Crash Course in Implementation Theory. Social Choice and Welfare, ${ }^{\circ}$ 18, p. 655708, 2001.

JUSTEN FILHO, M. Estado Democrático de Direito e responsabilidade civil do Estado: a questão dos precatórios. Revista de Direito Público da Economia, Belo Horizonte, ano 5, n. 19, p. 159-208, jul-set/2007.

LAFFONT, J.; MARTIMORT, D. The Theory of Incentives: the principal-agent model. New Jersey: Princeton University Press, 2002.

MASKIN, E.; SJOSTROM, T. Implementation theory. In: K. J. Arrow \& A. K. Sen \& K. Suzumura (ed.), Handbook of Social Choice and Welfare, vol. 1, p. 237-288. Amsterdam: North-Holland, 2002.

MENDES, M. J. Nota Informativa n 468. Consultoria Legislativa do Senado Federal, Brasília, 2006.

OLIVEIRA, A. F. Precatórios: aspectos administrativos, constitucionais, financeiros e processuais. Belo Horizonte: Fórum, 2005.

VALOR ECONÔMICO. Seis Estados e vários municípios deixam precatórios fora da dívida consolidada, 25/07/2011, http://www.valor.com.br/arquivo/900151/seis-estados-e-varios-municipios-deixam-precatorios-fora-da-divida-consolidada\#ixzz23Idew3wF, acessado em 12/8/2012. 